\title{
Rediscovery of a fossil dolichoderine ant lineage (Hymenoptera: Formicidae: Dolichoderinae) and a description of a new genus from South America
}

\author{
ALEXANDER L. WILD ${ }^{1} \&$ FABIANA CUEZZO ${ }^{2}$ \\ ${ }^{1}$ Department of Entomology, University of California at Davis, Davis, CA 95616, U.S.A.; alwild@ ucdavis.edu \\ ${ }^{2}$ CONICET - INSUE. Fac. de Ciencias Naturales e IML. Miguel Lillo 205. T4000JFE - San Miguel de \\ Tucumán, ARGENTINA
}

\begin{abstract}
We describe a new genus, Gracilidris Wild \& Cuezzo gen. nov., and a new species, G. pombero Wild and Cuezzo sp. nov., of dolichoderine ants (Hymenoptera: Formicidae: Dolichoderinae) from Paraguay, Brazil and Argentina based on the worker caste. These ants are morphologically similar to the extinct Gracilidris humilioides (Wilson 1985) comb. nov., known from a single Dominican amber fossil, that we redescribe and transfer to Gracilidris from Linepithema Mayr.
\end{abstract}

Key words: Formicidae, taxonomy, chaco, cerrado, neotropics

\section{Introduction}

The known richness of the South American ant fauna has increased substantially over the past two decades following the development of specialized collecting protocols (e.g., Agosti et al. 2000). Tropical wet forests have received the bulk of the recent sampling effort, but arid and semi-arid areas of South America remain relatively undersampled. These drier habitats have potential to yield a similar increase in ant diversity, including some older lineages of substantial phylogenetic importance. Here we report one such example, a discovery of extant populations of an undescribed dolichoderine taxon known previously from a single fossil specimen in Dominican Amber. In the present paper we describe a new genus and a new extant species based on the worker caste and propose a new combination for the fossil species Linepithema humilioides (Wilson). 
Material for this study was obtained from the following institutions (abbreviations between parenthesis): Museo Nacional de la Historia Natural del Paraguay, San Lorenzo, Paraguay (IBNP); Instituto-Fundación Miguel Lillo, Tucumán, Argentina (IFML); Museum of Comparative Zoology, Harvard University, Cambridge, Massachusetts, U.S.A. (MCZC); Museo de Zoologia de Sao Paulo, Sao Paulo, Brazil (MZSP). Type material was deposited in the following collections and institutions: Alexander L. Wild personal coll., Davis, California, U.S.A. (ALWC); The Natural History Museum, London, England, U.K. (BMNH); California Academy of Sciences, San Francisco, California, U.S.A. (CASC); Instituto-Fundación Miguel Lillo, Tucumán, Argentina (IFML); Natural History Museum of Los Angeles County, Los Angeles, California, U.S.A. (LACM); Museum of Comparative Zoology, Harvard University, Cambridge, Massachusetts, U.S.A. (MCZC); Museo de Zoologia de Sao Paulo, Sao Paulo, Brazil (MZSP); United States National Museum of Natural History, Washington, D.C., U.S.A. (USNM); and The Bohart Museum of Entomology, University of California, Davis, U.S.A. (UCDC).

Morphological measurements were made on a subset of worker specimens using a dual-axis Nikon stage micrometer with a precision of $0.001 \mathrm{~mm}$. Owing to a small amount of measurement error, we report measurements here to $0.01 \mathrm{~mm}$.

We employed a number of standard morphometric characters and indices. Head measurements are given with the head in full frontal view and the anterior clypeal margin and the posterior border of the head in the same focal plane. We consider ant heads to be prognathous, such that the clypeus is anterior and the frontal area is dorsal. Measurements are as follows:

HL - Head length. In full frontal view, the midline distance from the level of the maximum posterior projection of the posterior margin of the head to the level of the most anterior projection of the anterior clypeal margin.

HW - Head width. In full frontal view, the maximum width of the head.

SL - Antennal scape length. Measured from the apex of the first antennal segment to the base, exclusive of the radicle.

FL - Profemur length. In posterior view, measured along the longitudinal axis from the apex to the junction with the trochanter.

LHT - Metatibial length. In dorsal view, measured along the longitudinal axis from the apex to the level of the lateral condyles, excluding the medial proximal condyle.

PW - Pronotal width. In dorsal view, the maximum width of the pronotum.

WL - Weber's length. In lateral view, the distance between the anterior margin of the pronotum exclusive of the collar to the posterior margin of the metapleural bulla.

OI - Optical index. (Eye length)*(Eye width)/HW.

SI - Scape index. $100 *$ SL/HW.

CI - Cephalic index. 100*HW/HL. 
In addition to morphometric measurements, we examined a suite of morphological characters commonly used in ant systematics. These characters include pilosity, pubescence, body and appendage color, shape of the head, shape of the mesosoma, shape of the petiole, and mandibular dentition.

Scanning Electron Microscope images of Gracilidris pombero were made at UCDC with a Hitachi S3500-N scanning electron microscope on an uncoated paratype worker specimen. Images of G. pombero and G. humilioides were taken using the Syncroscopy Auto-Montage imaging and software system (http://www.syncroscopy.com) by April Nobile at CASC and by ALW at UCDC, respectively.

\section{Results}

Gracilidris Wild \& Cuezzo, gen. nov.

(worker Figs. 1-8, 12-14; map Fig. 11)

Type species: Gracilidris pombero (by present designation).

\section{Included species}

pombero Wild \& Cuezzo 2006

humilioides (Wilson 1985; Dominican amber)

\section{Worker diagnosis}

Small, slender dolichoderine ant. Petiole distinct, bearing a tall dorsal scale with apex narrowed and distinctly curved posteriad. Compound eyes located near longitudinal midpoint of head and touching lateral margins in full frontal view. Anterior margin of clypeus projecting forward in a broad convexity. Antennal scapes longer than head length. Dorsum of head, mesosoma, and metasoma exclusive of abdominal tergite 6 devoid of erect setae.

\section{Worker description}

HEAD. In full frontal view longer than broad and quadrate-oval in shape. Lateral margins convex, posterior margin straight. Compound eyes situated near longitudinal midpoint of head, touching lateral margins, and large in size, with at least 50 ommatidia (>130 in G. pombero). Ocelli absent. Antennae 12-segmented, scapes noticeably longer than head length (SI 138-167). Clypeus large and entire, without a median notch or concavity, and projecting forward with a broad, convex anterior margin. Hypostoma with a strong medial notch. Psammophore absent.

MOUTHPARTS. Palp formula 6:4. Maxillary palp segments generalized and of roughly equal length, except for a short proximal segment. Mandibles triangular with dentition as follows: strong apical tooth, a smaller subapical tooth, and a series of 8-12 
small teeth or denticles on masticatory margin. Basal angle indistinct and often bearing several denticles.

MESOSOMA. Pronotum and mesonotum freely articulating, not fused, and in lateral view forming a single continuous convexity. Pronotum rounded laterally. Propodeum depressed below the level of promesonotum. Dorsal and declivitous faces of propodeum subequal in length and meeting in an indistinct convexity. Propodeal spiracle located postero-laterally, at about $2 / 3$ height of declivitous face.

PETIOLE (abdominal segment 2). With a distinct dorsal scale that is taller than broad, inclined anteriorly, and achieving height of propodeal spiracle. Apex of scale narrowed into a point and distinctly curved posteriad, so that in lateral view anterior face of apical third of scale is convex and posterior face is slightly concave (Fig. 7). Venter of petiole with a weakly developed lobe.
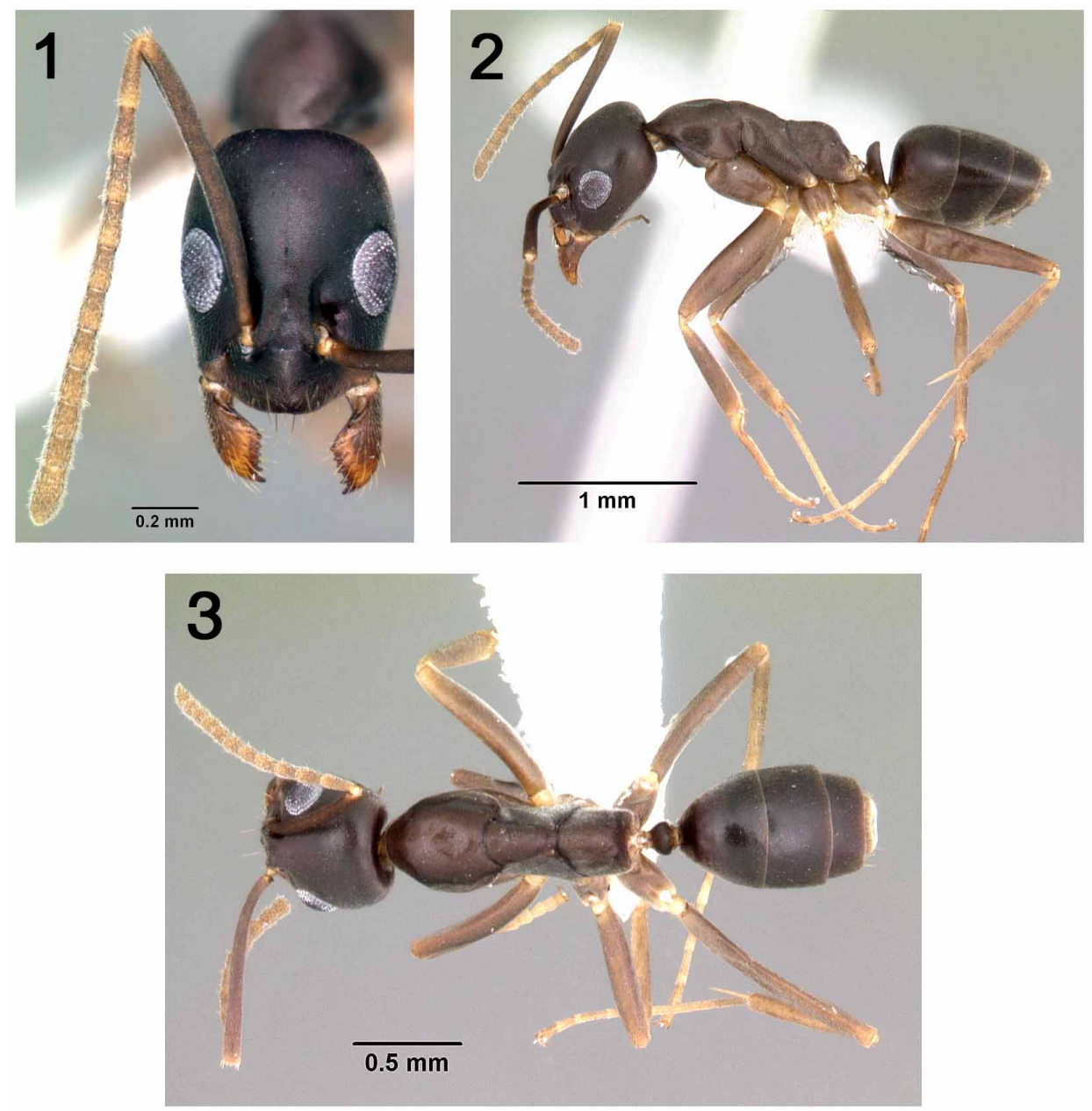

FIGURES 1-3. Montaged photographs of Gracilidris pombero, paratype worker from $5 \mathrm{~km} \mathrm{SE}$ Pozo Colorado, Pte. Hayes, Paraguay. 1. Head, full frontal view. 2. Body, lateral view. 3. Body, dorsal view. 
GASTER (abdominal segments 3-7). Gaster in dorsal view with four visible terga. Abdominal tergite 7 small, concealed under tergite 6, and oriented ventrally. Gaster in posterior view roughly triangular and slightly compressed laterally. First gastral segment (abdominal segment 3 ) with anterior tergosternal suture extending laterally from helcium. Ultimate abdominal sternite (abdominal sternite 7) folded medially in shape of a longitudinal keel.

GENERAL. Worker morphology generalized, somewhat elongate. Worker caste monomorphic. Integument thin and covered in a dense, fine pubescence. Proventriculus small, weakly developed, and unsclerotized, without phragma or visible pile, and with a dome-shaped cupola divided into 4 quadrats. Proventricular cupola only partly obscuring the bulb in lateral view, and about as wide or only slightly wider than the bulb.

\section{Discussion}

In Bolton's Identification guide to the ant genera of the world (Bolton 1994), Gracilidris will work through to the final couplet of the Neotropical dolichoderine key separating Linepithema and Azteca. Gracilidris will not key easily to either genus as it lacks the broad medial anterior clypeal concavity of Linepithema and does not match the mandibular dentition of Azteca. In Shattuck's Generic revision of the ant subfamily Dolichoderinae (Shattuck 1992b), Gracilidris will key through to couplet 17 of the worker key but does not match either option given in that couplet for clypeal configuration. Of all the Neotropical ant genera, Gracilidris most closely resembles Linepithema, but can be distinguished by a more lateral position of the eyes on the head, the relatively longer antennal scapes, and the distinct posteriad curve of the petiolar apex.

Other common dolichoderine genera may be separated from Gracilidris as follows. Azteca: worker caste polymorphic, petiolar node low, and clypeus not projecting forward. Dolichoderus: integument more sclerotized, declivitous face of propodeum concave in lateral view, and possessing hypostomal teeth. Dorymyrmex: with a distinct process or spine on propodeum, anterior clypeal margin not strongly projecting forward, and with a much stronger apical mandibular tooth. Forelius: anterior clypeal setae as long as the closed mandibles, petiole with a much smaller scale and obscured in dorsal view by abdominal tergite 3. Iridomyrmex: compound eyes in full frontal view in most species not touching the lateral margins of the head, anterior clypeal margin not projecting forward as a single convexity. Leptomyrmex: body and appendages much more elongate, petiolar scale lower and less developed. Tapinoma: petiole lacking a distinct scale and obscured in dorsal view by abdominal tergite 3. Technomyrmex: as for Tapinoma, petiole lacking a distinct scale and obscured in dorsal view by abdominal tergite 3 .

The relationship of Gracilidris to other dolichoderines is the subject of ongoing research by the authors (Cuezzo \& Wild, in preparation) and will not be reported in detail here. In support of the establishment of a new genus, however, preliminary results from three nuclear protein-coding genes indicate that the sequence divergence between $G$. 
zootaxa pombero and other dolichoderines is of a level similar to that observed among other 1142 dolichoderine lineages currently treated as genera. Additionally, the establishment of Gracilidris does not appear to render any currently-recognized genus paraphyletic.

Etymology

Gracilidris refers to the slender habitus of this ant.

\section{Gracilidris pombero Wild \& Cuezzo, sp. nov.}

(worker Figs. 1-8, 10; nest Fig. 9; distribution Fig.11)

Type material examined

Holotype. Worker. Paraguay, Pte. Hayes: 5k SE Pozo Colorado. 140m. 23³3.129’ S 58 45.853' W, 5.xii.2002, A.L. Wild acc. no. \#1766 (IBNP).

Paratypes. Series of 20 workers, same data as holotype, acc. nos. \#1734, 1736, 1766 (ALWC, BMNH, CASC, IFML, LACM, MCZC, MHNG, MZSP, UCDC, USNM).

Additional material examined

Argentina: Santiago del Estero: Copo National Parq. (5w, IFML). Brazil: Bahia: Ilheus, CEPEC, specimen not directly examined, (photographic internet record, \#4830: http://research.amnh.org/entomology/social_insects/tempcepecline.html, available in 2002 and apparently offline as of August 2005). Maranhão: Balsas, Gerais de Balsas $08^{\circ} 34^{\prime}$ S 046²42.6’W xi.1999-iii.2000, Brandão et al (2w, MZSP). Mato Grosso: Mpio. Várzea Grande, Souza Lima, 25.i.1985, J. C. Trager (3w, MZSP). São Paulo: Agudos, xii.1957, C. Gilbert (2w, MZSP).

\section{Worker measurements}

Holotype: HL 0.87, HW 0.67, SL 0.94, FL 0.87, LHT 0.95, PW 0.53, WL 1.28, OI 5.4, SI 141, CI 76.

Others $(\mathrm{n}=14)$ : HL $0.80-0.93$, HW $0.62-0.71$, SL $0.89-1.08$, FL 0.72-0.99, LHT 0.89-1.14, PW 0.47-0.57, WL 1.16-1.46, OI 4.0-6.9, SI 138-154, CI 76-81.

\section{Worker description}

As given in the generic description, but with the following additional details:

Head in full frontal view longer than broad (CI 76-81) and quadrate-oval in shape. Lateral margins evenly convex and the head no wider posterior to than anterior to the eyes. Compound eyes large (OI 4.0-6.9), consisting of 130-150 ommatidia, situated near the longitudinal midpoint of the head in full frontal view. Anterior clypeal margin usually bearing a single straight, short, forward-projecting median seta, a longer pair of setae just lateral of the midline that are about half the length of the masticatory margin of the mandibles, and an irregular number (2-6) of small setae lateral to these (Fig. 6). 
Mandibular dentition variable but usually as follows: strong apical tooth, a smaller subapical tooth, a small third tooth, a strong fourth tooth, and the remaining 3 teeth small, spaced more or less evenly along the masticatory margin and separated from each other by 1-3 denticles. Basal angle of the mandible indistinct and bearing 2-4 denticles.
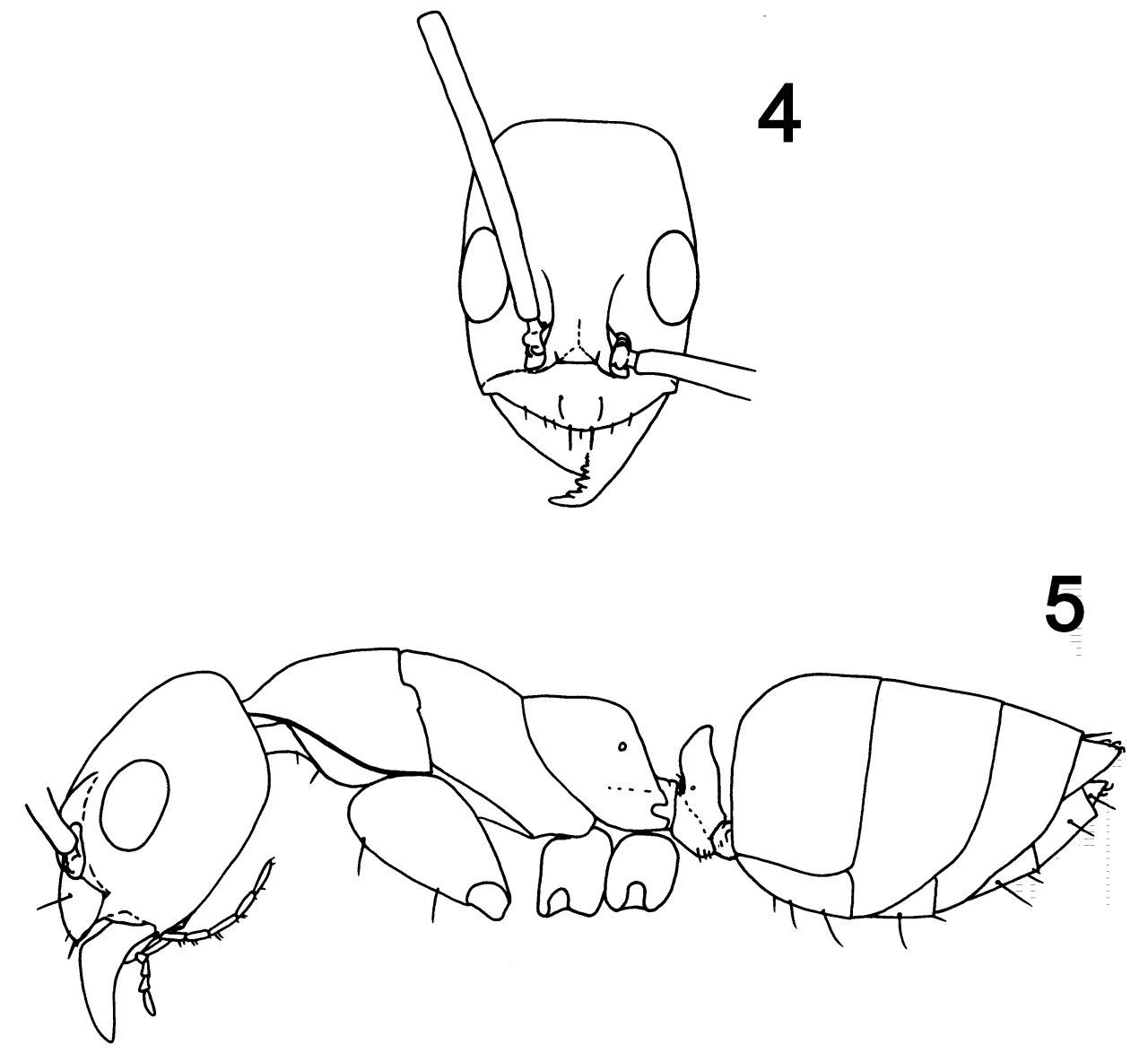

FIGURES 4-5. Line drawings of Gracilidris pombero, paratype worker from $5 \mathrm{~km}$ SE Pozo Colorado, Pte. Hayes, Paraguay. 1. Head, full frontal view. 2. Body, lateral view.

Dorsal surfaces of ant head, mesosoma, and metasoma devoid of erect setae, except abdominal segment 6 which bears a pair of setae oriented posteriorad. Entire surface of body including legs, antennal scapes, and the proximal half of the mandibles covered in a dense, fine pubescence. Pubescence also contains fine appressed hairs twice as long as the adjacent hairs, and evenly spaced about as far apart as their length over the body and appendages (Fig. 8). These can be difficult to see without the correct lighting, and are most visible on the gaster. Ventral surfaces of the mesosoma, coxae, and metasoma with a few erect setae. Integument shagreened, ant appearing dull to lightly shining but never opaque.

Color varying from body and appendages dark brown (Paraguay, Bahia, Maranhão), to 

white.
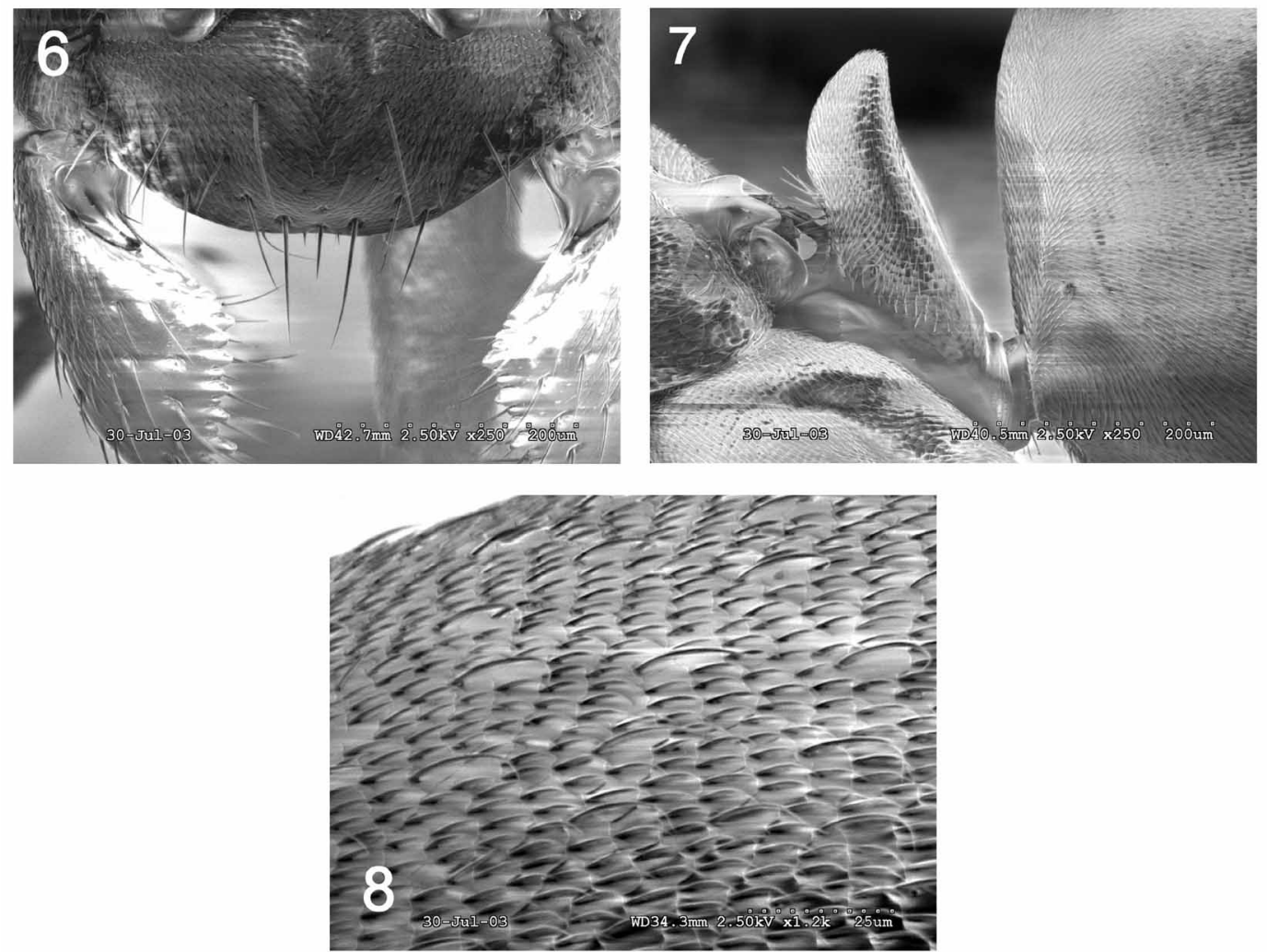

FIGURES 6-8. Scanning electron micrographs of Gracilidris pombero, paratype worker from 5 km SE Pozo Colorado, Pte. Hayes, Paraguay. 6. Clypeus, dorsal view. 7. Petiole, lateral view. 8. Abdominal tergite 3 (= gastric tergite 1), surface sculpture.

\section{Discussion}

Body proportions and color vary geographically among populations of G. pombero. In particular, specimens from Paraguay and Argentina are darker and have relatively shorter appendages than Brazilian specimens. Given that this variation is allopatric, however, and given the limited material available for study, we feel it is preferable to place all forms within a single species until more material becomes available.

\section{Biology}

In the two collection series where nesting information was noted (the Paraguayan type series and the Mato Grosso series), colonies were in soil with the nest entrance consisting of a small earthen turret. The turret of the type series nest in Paraguay was only a few millimeters tall and opened at ground level on one side (Fig. 9), so that the nest entrance 
was cryptic and concealed from above. There appeared to be only one nest entrance. A low level of activity at the entrance of the type series nest and the small number of workers (n $=25$ ) collected during a partial nest excavation suggests a small colony size.
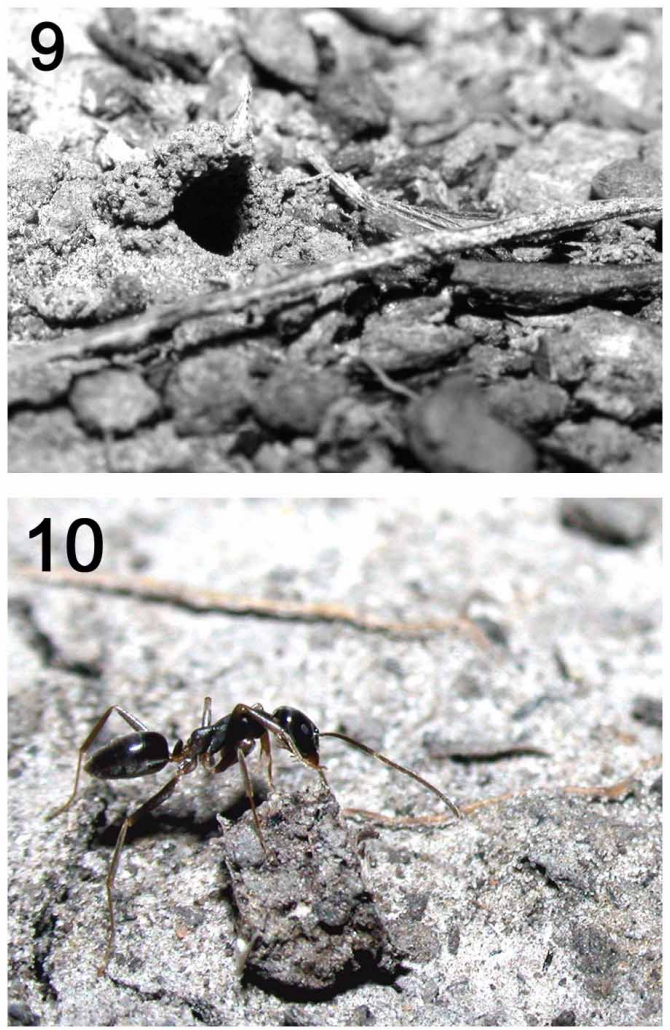

FIGURES 9-10. 9, Nest entrance of Gracilidris pombero type series colony, $5 \mathrm{~km}$ SE Pozo Colorado, Pte. Hayes, Paraguay. Oblique lateral view showing the one-sided turret. 10. Photograph of foraging Gracilidris pombero from type series, $5 \mathrm{~km}$ SE Pozo Colorado, Pte. Hayes, Paraguay.

The collection records of G. pombero indicate that it inhabits low scrub forests of the type found in cerrado and chaco habitats. The specimens from Maranhão were collected at a sardine bait in cerrado scrub forest near the edge of a soybean field. The specimen from Bahia, Brazil was collected in a small primary forest fragment in a Cocoa plantation. The Mato Grosso, Brazil collection was from grazed cerrado, and the Paraguayan type series came from a lightly grazed Copernicia alba palm forest in the humid chaco.

Gracilidris ants are probably noctural, which may partly explain their rarity in collections. At the type locality, single foraging workers were collected at dusk and after dark on two separate nights, and visual searches and baits during the day at the same location did not yield any workers. In the field, workers appear elongate, their gaster held horizontally (Fig. 10), and their movements are smooth and deliberate.

Reproductive castes, brood, colony structure, and life history are unknown. 
Pombero is a mythical nocturnal figure in Guaraní folklore. The name is applied here as a noun in apposition in reference to the nocturnal activity pattern of this species.

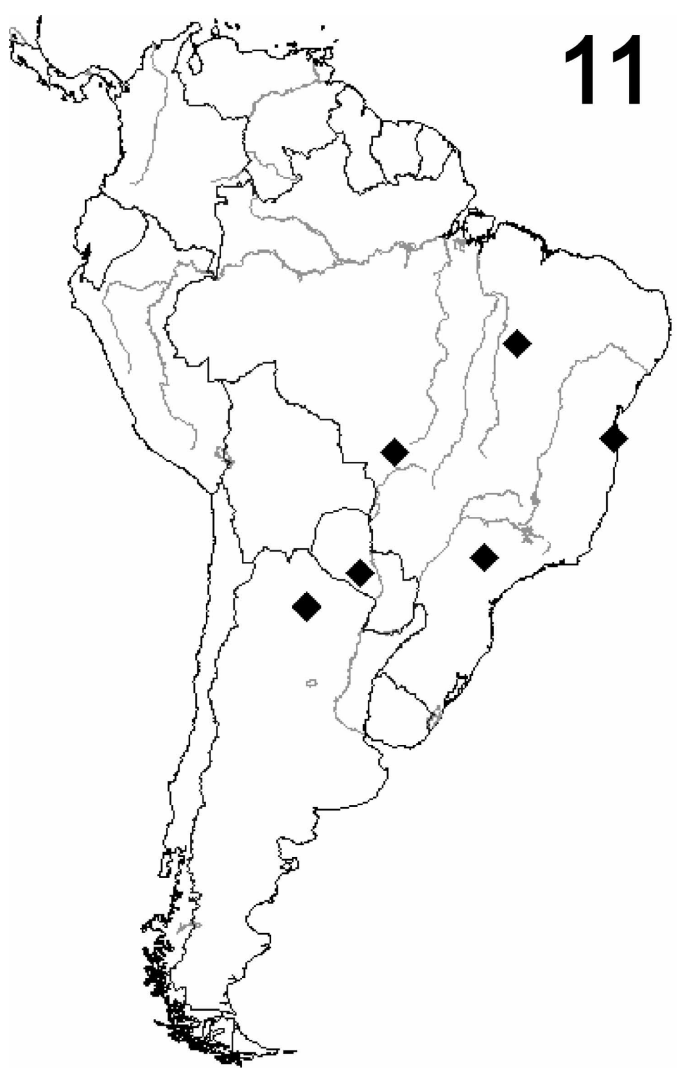

FIGURE 11. Distribution of Gracilidris pombero in South America, based on museum records at IBNP, IFML, MZSP, and an internet photographic record at http://antbase.org.

\section{Gracilidris humilioides (Wilson 1985), comb. nov.}

(Figs. 12-14)

Iridomyrmex humilioides Wilson 1985: 33.

Linepithema humilioides (Wilson): Shattuck 1992a: 16. First combination in Linepithema.

Type material examined

Holotype. Worker. Dominican amber [no further data] (MCZC).

Worker measurements

Holotype: HL 0.67, HW 0.44, SL 0.74, FL 0.53, LHT 0.62, PW 0.37, OI 1.8, SI 167, CI 66. 

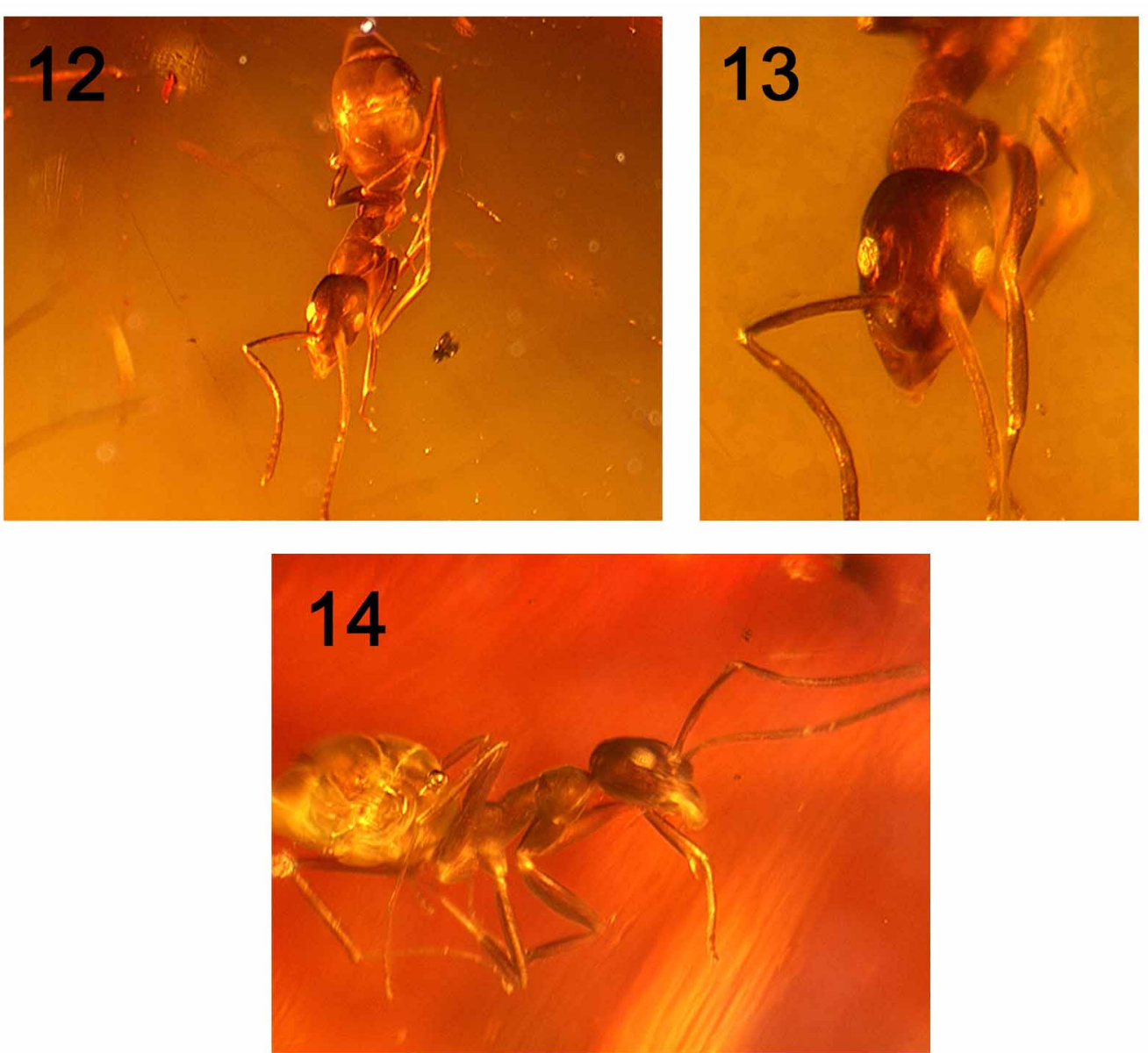

FIGURES 12-14. Montage images of Gracilidris humilioides (Wilson), holotype worker from the Dominican amber. 12. Body, oblique dorsal view. 13. Head, full frontal view. 14. Body, oblique lateral view.

\section{Worker description}

As given in generic description, but with some characters obscured, including the mandibular dentition and the petiole. Additional details include:

Head in full frontal view longer than broad $(C I=66)$. Sides of head subparallel and convex, head slightly wider posterior than anterior to compound eyes. Compound eyes of moderate size $(\mathrm{OI}=1.8)$, with about 70 ommatidia, and surpassing lateral margins in full frontal view.

Dorsal surfaces of head, mesosoma, and metasoma devoid of erect setae.

\section{Discussion}

This species is known from a single worker specimen, briefly described by Wilson 

definition encompassing both old world and new world forms. When Shattuck (1992a) redefined Iridomyrmex and moved most of the new world species into Linepithema, he transferred humilioides as well even though humilioides lacks many of the apomorphies that define extant Linepithema. In particular, humilioides does not possess the medially concave anterior clypeal margin of Linepithema, and the eyes of humilioides are located considerably more posterior and lateral on the head than in any of the extant Linepithema species.

The affinity of humilioides with Gracilidris is supported by the position and shape of the eyes, the length of the legs and antennal scapes, the reduced pilosity, and by the shape and forward projection of the clypeus. This combination of characters is unique among the dolichoderines. However, this association should be regarded as tentative. Both humilioides and pombero are in many respects generalized dolichoderine ants, and some of their similarity may be pleisiomorphic. Additionally, many key characters of Gracilidris are not visible in the fossil including, unfortunately, the petiole.

\section{Acknowledgements}

We thank Phil Ward for commenting on an early version of the manuscript, April Nobile (CASC) for imaging G. pombero, Roberto Brandão (MZSP) for loaning invaluable Brazilian material, and Stefan Cover (MCZC) for loaning the type specimen of $G$. humilioides. This work was supported by U.C. Davis Center for Biosystematics, a United States National Science Foundation grant \#0234691 to ALW, and by Conicet and FONCyT, PICT 12605 programs of FC.

\section{References}

Agosti, D., J.D. Majer, L.E. Alonso and Schultz, T.R. (2000) Ants: standard methods for measuring and monitoring biodiversity. Smithsonian Institution Press, Washington, DC, 280 pp.

Bolton, B. (1994) Identification Guide to the Ant Genera of The World. Harvard University Press, Cambridge, MA, $222 \mathrm{pp}$.

Shattuck, S.O. (1992a) Review of the dolichoderine ant genus Iridomyrmex Mayr with descriptions of three new genera (Hymenoptera: Formicidae). Journal of the Australian Entomological Society, 1, 13-18.

Shattuck, S.O. (1992b) Generic revision of the ant subfamily Dolichoderinae. Sociobiology, 21, 1181.

Wilson, E.O. (1985) Ants of the Dominican amber. 3. The subfamily Dolichoderinae. Psyche, 92, 17-37. 